\title{
Polymorphism and Conformational Equilibrium of Nitro-Acetophenone in Solid State and under Matrix Conditions
}

\author{
Łukasz Hetmańczyk ${ }^{1}$, Przemysław Szklarz ${ }^{2}$ D, Agnieszka Kwocz ${ }^{2}$, Maria Wierzejewska ${ }^{2}$, \\ Magdalena Pagacz-Kostrzewa ${ }^{2} \mathbb{D}$, Mikhail Ya. Melnikov ${ }^{3}$, Peter M. Tolstoy ${ }^{4}\left(\mathbb{D}\right.$ and Aleksander Filarowski ${ }^{2,5, *(\mathbb{D})}$
}

1 Faculty of Chemistry, Jagiellonian University, Gronostajowa 2, 30-387 Kraków, Poland; hetmancz@chemia.uj.edu.pl

2 Faculty of Chemistry, Wrocław University, I14 F. Joliot-Curie st., 50-383 Wrocław, Poland; przemyslaw.szklarz@chem.uni.wroc.pl (P.S.); agnieszka.kwocz@chem.uni.wroc.pl (A.K.); maria.wierzejewska@chem.uni.wroc.pl (M.W.); magdalena.pagacz-kostrzewa@chem.uni.wroc.pl (M.P.-K.)

3 Department of Chemistry, Moscow State University, F. Joliot-Curie 14, 119991 Moscow, Russia; melnikov46@mail.ru

4 Institute of Chemistry, St. Petersburg State University, Universitetskij pr. 26, 198504 St. Petersburg, Russia; peter.tolstoy@spbu.ru

5 Frank Laboratory of Neutron Physics, Joint Institute of Nuclear Research, 141980 Dubna, Russia

* Correspondence: aleksander.filarowski@chem.uni.wroc.pl; Tel.: +48-71-3757283

\section{check for} updates

Citation: Hetmańczyk, Ł.; Szklarz, P.; Kwocz, A.; Wierzejewska, M.; Pagacz-Kostrzewa, M.; Melnikov, M.Y..; Tolstoy, P.M.; Filarowski, A. Polymorphism and Conformational Equilibrium of Nitro-Acetophenone in Solid State and under Matrix Conditions. Molecules 2021, 26, 3109. https://doi.org/10.3390/molecules 26113109

Academic Editor: Mirosław Jabłoński

Received: 11 May 2021

Accepted: 21 May 2021

Published: 22 May 2021

Publisher's Note: MDPI stays neutral with regard to jurisdictional claims in published maps and institutional affiliations.

Copyright: (c) 2021 by the authors. Licensee MDPI, Basel, Switzerland. This article is an open access article distributed under the terms and conditions of the Creative Commons Attribution (CC BY) license (https:/ / creativecommons.org/licenses/by/ $4.0 /)$.
Abstract: Conformational and polymorphic states in the nitro-derivative of $o$-hydroxy acetophenone have been studied by experimental and theoretical methods. The potential energy curves for the rotation of the nitro group and isomerization of the hydroxyl group have been calculated by density functional theory (DFT) to estimate the barriers of the conformational changes. Two polymorphic forms of the studied compound were obtained by the slow and fast evaporation of polar and non-polar solutions, respectively. Both of the polymorphs were investigated by Infrared-Red (IR) and Raman spectroscopy, Incoherent Inelastic Neutron Scattering (IINS), X-ray diffraction, nuclear quadrupole resonance spectroscopy (NQR), differential scanning calorimetry (DSC) and density functional theory (DFT) methods. In one of the polymorphs, the existence of a phase transition was shown. The position of the nitro group and its impact on the crystal cell of the studied compound were analyzed. The conformational equilibrium determined by the reorientation of the hydroxyl group was observed under argon matrix isolation. An analysis of vibrational spectra was achieved for the interpretation of conformational equilibrium. The infrared spectra were measured in a wide temperature range to reveal the spectral bands that were the most sensitive to the phase transition and conformational equilibrium. The results showed the interrelations between intramolecular processes and macroscopic phenomena in the studied compound.

Keywords: polymorphism; isomerization; phase transition; nitro group; matrix isolation; IINS; FT-IR; Raman; X-ray; NQR; DSC; DFT

\section{Introduction}

The aim of this paper is to investigate polymorphic and conformational states of the nitro-derivative of $o$-hydroxy acetophenone. The study explains the influence of the intramolecular hydrogen bond on the phase transition and conformational equilibrium. The expected intramolecular dynamic processes in the $o$-hydroxy acetophenone molecule are the rotation of the nitro group and isomerization of the hydroxyl group (Scheme 1). These processes define such macroscopic phenomena as polymorphism, phase transition and the existence of stable isomers under different conditions. The study of conformational isomerism is a very important issue in modern chemistry for determining and modelling the physical-chemical properties of new materials [1-4] and pharmaceutical compounds [5-8]. 
It must be stressed that an intramolecular hydrogen bond strongly influences the isomerization equilibrium $[9,10]$. For deeper insight into the hydrogen-bonding effect on the polymorphic states and isomerization we applied a wide variety of research methods (DFT, X-ray, DSC, NQR, IINS, IR and Raman) in different environments and over a wide temperature range. It is worth noting that the method of matrix isolation was unique in its ability to trace metastable states and help interpret complex reactions [11-14]. Moreover, investigations of objects with hydrogen bonding by IINS [15-18] and NQR $[19,20]$ techniques are useful.<smiles>CC(=O)c1cc(Cl)cc([N+](=O)[O-])c1O</smiles>

(A)<smiles>CC(=O)c1cc(Cl)cc([N+](=O)[O-])c1O</smiles>

(B)<smiles>CC(=O)c1cc(Cl)cc([N+](=O)[O-])c1O</smiles>

(C)

Scheme 1. Schemes of intramolecular hydrogen bonding isomerization $(\mathbf{A}, \mathbf{B})$ and nitro group rotation (C) for 5-chloro-3-nitro-2-hydroxyacetophenone (CNK).

In this paper the research methodology followed the following sequence: First, DFT calculations were performed to detect stable and metastable states of the studied molecule, 5-chloro-3-nitro-2-hydroxyacetophenone (CNK). The first stage of the studies predicted that CNK would crystallize into two polymorphic forms; therefore, its structural properties were analyzed by $\mathrm{X}$-ray diffraction at different temperatures, and both polymorphs were studied by the DSC method to detect phase transition, which was found in one of the polymorphs and verified by ${ }^{35} \mathrm{Cl}$ NQR measurement. Spectral properties of both polymorphs were investigated by IINS, IR and Raman, and computational (DFT) methods in different states to obtain exhaustive information about which vibrational bands (as well as their assignments) were the most sensitive to the phase transition. The assignments of the spectral bands were accomplished on the basis of the H/D substitution of bridge hydrogen $(\mathrm{OH} \rightarrow \mathrm{OD})$ and Potential Energy Distribution (PED) analysis. Spectral infrared studies of the two isotopologues $(\mathrm{OH}$ and $\mathrm{OD}$ ) showed the presence of two conformers (A and $\mathrm{B}$, Scheme 1) under the argon matrix condition.

\section{Results and Discussion}

At first, the studies dwelt on the DFT calculations of the potential curves to detect stable and metastable states of the molecule according to the concepts presented in the review paper by Bernstein [2]. The information about the energy difference between the global and local minima as well as the height of energy barriers made it possible to predict the presence of a particular conformer or polymorph depending on the environment. For the studied molecule it was logical to consider two possible intramolecular processesreorientation of the hydroxyl group and rotation of the nitro group (Scheme 1). Therefore, the dependencies of the potential energy on the turning angle of the hydroxyl and acetyl groups were obtained by DFT calculations, which were performed under step-by-step 
changes to the torsional angle while all other geometric parameters of the molecule were optimized. The calculation of potential energy dependence on the $\Theta$ angle of turning the nitro group is given by the equation $\Delta E=f(\Theta)$, where $\Delta E=E_{\min }-E_{\mathrm{i}} ; E_{\min }$ is the minimal energy of the system; and $E_{\mathrm{i}}$ is the energy of the system for each fixed $\Theta$ angle). The result demonstrated that the energy barrier was rather small and equaled $0.78 \mathrm{kcal} / \mathrm{mol}$ when the $\Theta$ angle equaled 0 degrees (Figure 1 ).

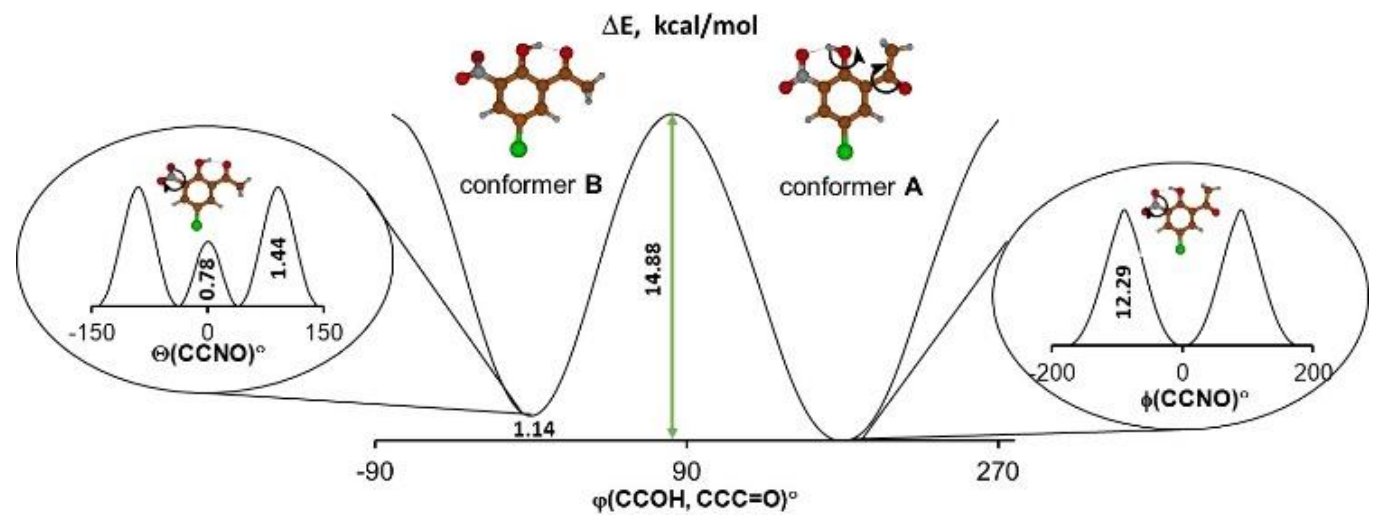

Figure 1. The calculated (B3LYP/6-311++G(2d,2p)) potential energy curves for the intramolecular hydrogen bond transformation (picture in the centre) and the nitro group rotation (picture in the left related to conformer $\mathrm{B}$ and picture in the right related to conformer $\mathrm{A})$.

Such a result may seem unconvincing because the torsional angle at 0 degrees (a flat molecule) is usually characterized by minimal potential energy because of $\pi$-electronic coupling between the nitro group and phenyl moieties. However, the studied molecule displayed a significant steric repulsion between the oxygen of the nitro group and the oxygen of the hydroxyl group, which counteracts the $\pi$-electronic coupling. Such steric repulsion results in the appearance of an energy barrier $(\Delta E=0.78 \mathrm{kcal} / \mathrm{moL})$ at $\Theta=0^{\circ}$ (Figure 1). Notably, this barrier is not large; thus, the nitro group can easily change its position with respect to the phenyl ring. The process of reorientation of the hydroxyl group leading to the transition from conformer A to conformer B is more complicated and is presented in Supplementary Materials (Supplementary Materials, Figure S1). Judging from the calculated energy barrier of $14-15 \mathrm{kcal} / \mathrm{mol}$, one expected the existence of both conformational forms at a reasonable temperature [21]. Taking these findings into account, we assumed that the studied compound featured polymorphism brought about by the rotation of the nitro group, or by a significant conformational change introduced by the reorientation of the hydroxyl group.

We performed comprehensive studies to trace polymorphs, phase transitions and conformational change. Two polymorphs of the CNK compound were obtained by slow recrystallization from methanol (polymorph I) and fast re-crystallization from chloroform (polymorph II). X-ray studies of polymorphs I and II showed that they crystallized in a Pccn $(\mathrm{T}=200 \mathrm{~K})$ and P21/c $(100 \mathrm{~K})$ space group, respectively. The comparison of the structures of the polymorphs clearly showed the difference in the position of the nitro group (Figure 2 and SM Figures S2 and S3). The disoriented position of this group in polymorph I points to significant dynamics in the solid state. The crystal cell of polymorph II is characterized by a more defined orientation of the nitro group. The nitro groups of polymorph I are able to rotate, but the nitro groups of polymorph II are not since in the crystal cell of polymorph II the molecules are packed in a way that turns the nitro groups and blocks the rotation. The studies of both polymorphs were carried out by DSC to detect a phase transition. The DSC measurements of both polymorphs showed the presence of a phase transition for polymorph I at $109.8 \mathrm{~K}$ (cooling)/114.5 K (heating) (Figure S4, SM) and the absence of a phase transition for polymorph II. The phase transition is reversible and the transformation is enantiotropic. 

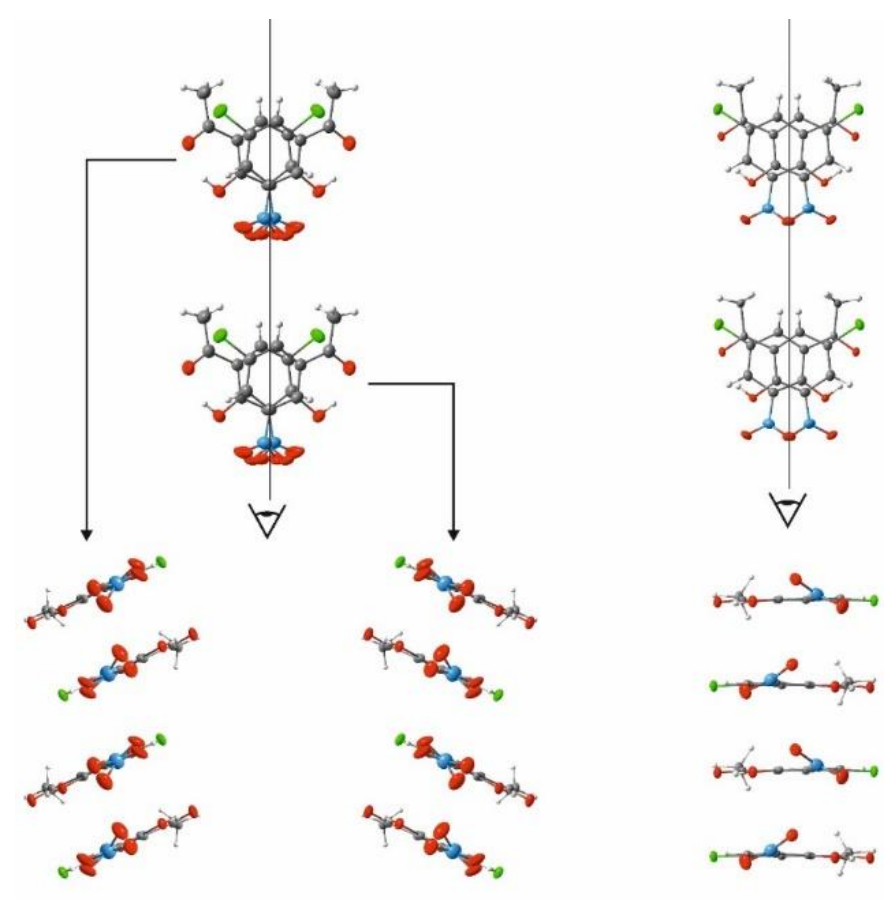

Figure 2. Selected view of the molecular packing of polymorph I (left side) and polymorph II (right side).

The comparison of the structural data and the packing of the molecules in the crystal cell of both polymorphs made it possible to conclude that the phase transition was conditioned by the following phenomenon. A decrease in temperature tightened the packing of the molecules in the cell and, therefore, caused a stronger interaction between the nitro groups. Polymorph II featured "jagged" nitro groups, which evoked the stable position of molecules in the crystal cell upon temperature decrease. Polymorph I lacked this phenomenon, having the possibility of a looser nitro-group rotation at room temperature, which stopped when the temperature was lowered. The decreasing temperature led to stronger interactions between nitro groups and shifted the molecules towards each other, triggering the phase transition. Such a conclusion was verified by comparing the packaging of CNK to that of the structurally similar 5-methyl-3-nitro-2-hydroxyacetophenone (MNK) [22]. For MNK, the nitro groups were oppositely directed and not able to interact strongly, so they did not provoke tensions in the crystal cell. Therefore, the structurally close MNK did not exhibit phase transition and polymorphism (cf. Figure S5, SM).

The phase transition in CNK was detected on the basis of NQR measurements. NQR was successfully used in the research of compounds with intermolecular [23] and intramolecular hydrogen bonds [24]. NQR studies revealed that the ${ }^{35} \mathrm{Cl}$ signal shifted to high frequencies (from 35.85 to $36.5 \mathrm{MHz}$ ) when the temperature fell from 300 to $120 \mathrm{~K}$ (the temperature of phase transition), whereas the signal was quite stable at temperatures below the transition state (Figure 3). A similar trend was observed for 1,3-diazinium hydrogen chloranilate monohydrate [25], morpholinium hydrogen chloranilate [26] and p-dichlorobenzene [27].

After comparing the structural data and the crystal packing of both polymorphs we concluded that the polymorphism and phase transition were conditioned by the position of the nitro group. Based on experimental data, this conclusion was in accordance with theoretical predictions. 


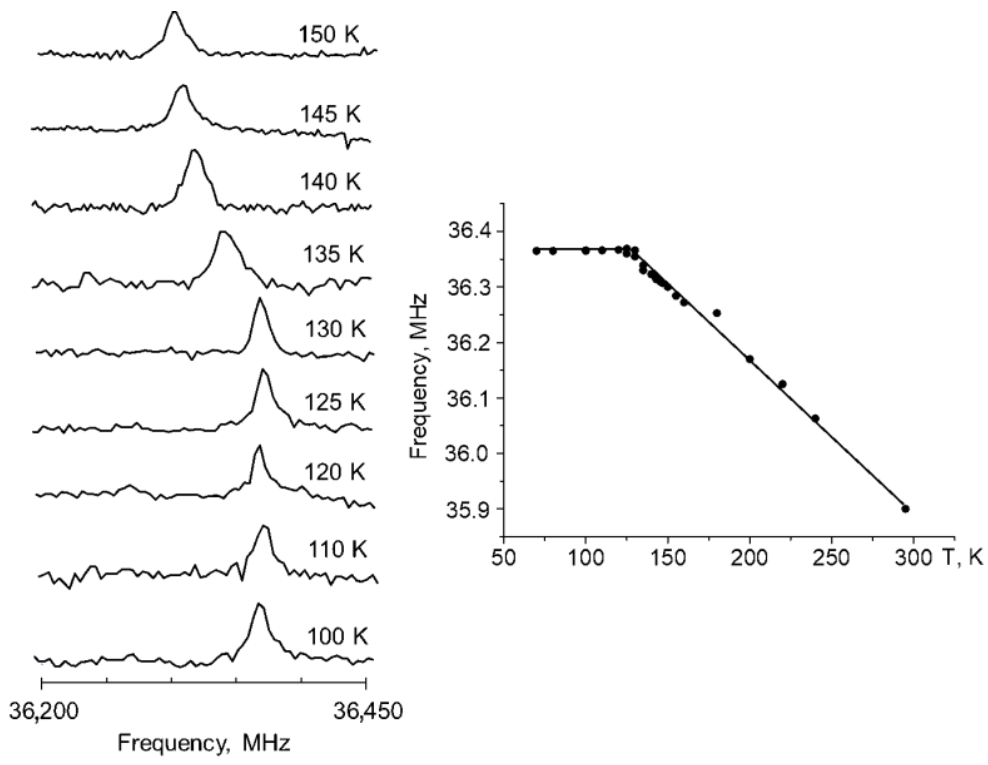

Figure 3. The ${ }^{35} \mathrm{Cl}$ NQR spectra (left side) and the temperature dependence of the ${ }^{35} \mathrm{Cl} \mathrm{NQR}$ frequency (right side) of 5-chloro-3-nitro-2-hydroxyacetophenone.

\subsection{Detection of Polymorphs in the Solid State and Isomers under the Matrix Condition by} Spectroscopic Methods

To detect the spectral bands that are the most sensitive to polymorphic and conformational changes as well as to phase transition, we performed an analysis of the vibrational spectra measured in solid state and under the matrix condition. To that end, IR, Raman and IINS spectra of the studied compound and its deuterated derivative $(\mathrm{OH} \rightarrow \mathrm{OD})$ were measured in the wide spectral and temperature ranges $\left(50-4000 \mathrm{~cm}^{-1}, 300-5 \mathrm{~K}\right.$, Figures 4 and 5 and SM Figures S6-S8). The analysis of the spectra and the assignments of the bands were based on DFT and PED calculations (Tables S2-S5, SM). Below, the description of the spectra measured in the solid state and the matrix isolation condition is presented, on the basis of which the isomeric equilibrium analysis was carried out.

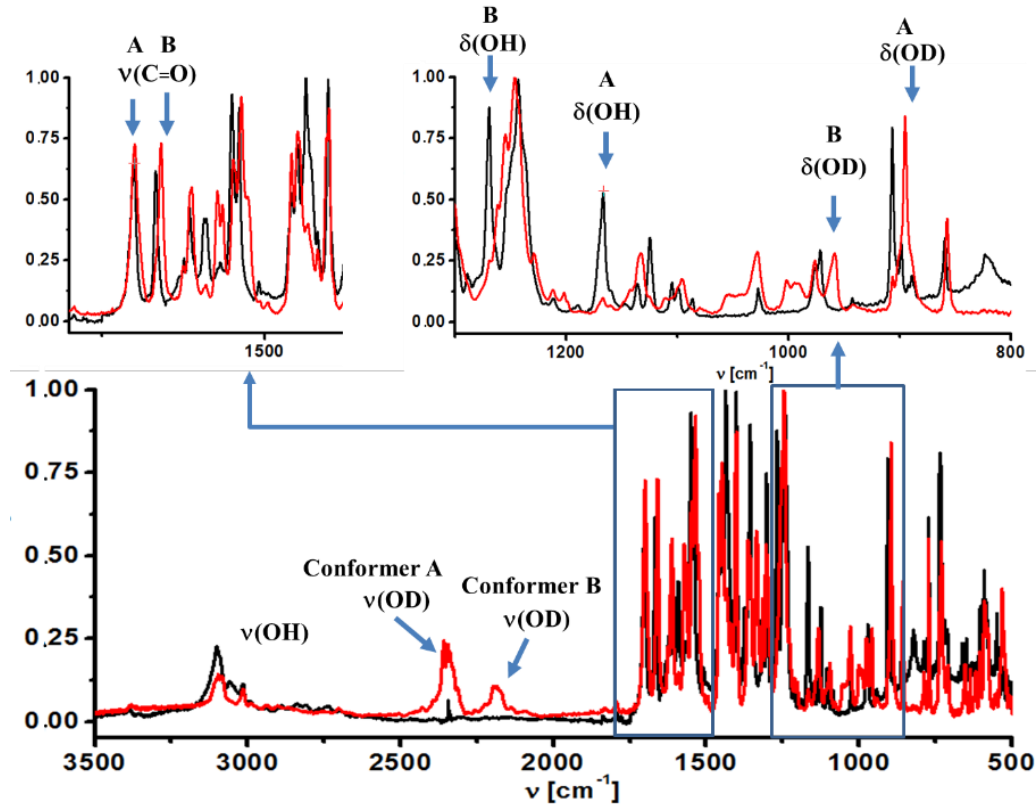

Figure 4. Matrix isolation IR spectra (in Ar) of 5-chloro-3-nitro-2-hyroxyacetophenone (black line) and its deuterated derivative (red line). 


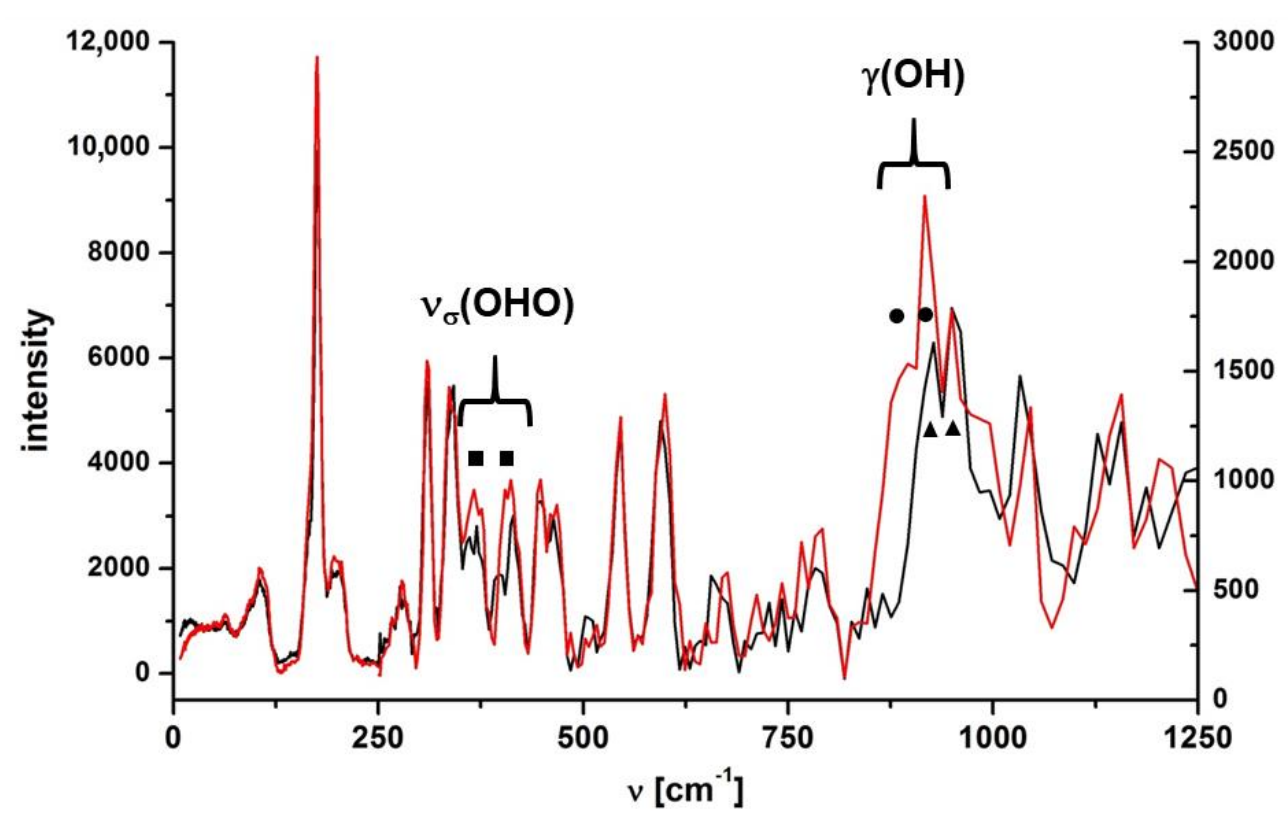

Figure 5. IINS spectra of CNK polymorph I (red line) and its deuterated analogue (black line). The IINS spectra were aligned and normalized in $0-250 \mathrm{~cm}^{-1}$ and $250-1250 \mathrm{~cm}^{-1}$ regions, separately.

\subsubsection{The $v(\mathrm{OH})$ Stretching Mode}

The adequate assignments of the bands of stretching $(v(\mathrm{OH}))$, in-plane $(\delta(\mathrm{OH}))$ and out-of-plane $(\gamma(\mathrm{OH}))$ bending modes of the hydroxyl group, as well as the isotope effects of these vibrations caused by the replacement of the bridged hydrogen by deuterium $(\mathrm{OH}$ $\rightarrow$ OD) was completed.

Solid state. When comparing the infrared spectra of deutero-(CNK-OD) and nondeutero-(CNK) derivatives of the studied compound, the band at $3000-2100 \mathrm{~cm}^{-1}$ in the IR spectra recorded in the solid state was assigned to the $v(\mathrm{OH})$ stretching mode due to its shift to $2100-2000 \mathrm{~cm}^{-1}$ after deuteration (Figure S6, SM). It was necessary to underline that the measured infrared spectra in the solid state did not reveal the intense band at $3100 \mathrm{~cm}^{-1}$ that was assigned to the stretching vibration of the hydroxyl group, which is hydrogen bonded with the nitro group (cf. spectra of CNK and o-nitro-phenol [28]). This fact confirmed the absence of conformational form $\mathbf{A}$ of the studied compound in the solid state. The result agreed with the presented X-ray study.

Matrix condition. The analysis of the $v(\mathrm{OH})$ band in the infrared spectrum measured under the matrix conditions does not provide a clear proof for the presence of two conformers. The reason is the overlapping of $v(\mathrm{OH})$ bands of both conformers and $v(\mathrm{CH})$ bands. However, two bands at $2185 \mathrm{~cm}^{-1}$ and $2350 \mathrm{~cm}^{-1}$ appear in the spectrum of CNK-OD; they are assigned to the $v(\mathrm{OD})$ vibration of conformers A and B (Figure 4), respectively. This result manifests the presence two conformational forms under the matrix condition.

\subsubsection{The $\delta(\mathrm{OH})$ and $\gamma(\mathrm{OH})$ Bending Modes}

Solid state. The in-plane bending mode $(\delta(\mathrm{OH}))$ was hard to analyze because of an uncharacteristic vibration in the solid state. According to PED analysis of the spectra calculated by the DFT method, this vibration was strongly coupled to the stretching vibrations of the phenyl ring (1563 and $1433 \mathrm{~cm}^{-1}$, Table S2, SM).

A broad band at $860 \mathrm{~cm}^{-1}$ for polymorph I and the band at $838 \mathrm{~cm}^{-1}$ for polymorph II (Table S2 and Figure S7, SM) were assigned to the out-of-plane mode of the hydroxyl group $(\gamma(\mathrm{OH}))$ in IR spectra measured in the solid state. The bands at $860 \mathrm{~cm}^{-1}$ and $838 \mathrm{~cm}^{-1}$ narrowed down drastically under the deutero replacement, and new bands arose at $628 \mathrm{~cm}^{-1}$ and $624 \mathrm{~cm}^{-1}$ in the CNK-OD spectra (Figure S6, ESI). These bands were assigned to the $\gamma(\mathrm{OD})$ mode according to ISR $=1.35$ (ISR-isotopic spectroscopic ratio). 
Matrix condition. As for in-plane and out-of-plane bending modes, a more distinct picture (due to the absence of the overlapping bands) was observed in IR spectra measured under the matrix condition. In these spectra, obvious changes to two bands at $1269 \mathrm{~cm}^{-1}$ and $1166 \mathrm{~cm}^{-1}$ appeared after deuteration. They completely disappeared after deuteration and new bands appeared at $959 \mathrm{~cm}^{-1}$ and $895 \mathrm{~cm}^{-1}$ in the CNK-OD spectrum (Figure 4). According to the observed changes and the calculated isotopic ratio (ISR $=1.32$ ), these two bands were assigned to the $\delta(\mathrm{OH})$ and $\delta(\mathrm{OD})$ modes of conformer $\mathbf{B}$ and conformer A, respectively (Table S3, SM). Rather broad and weak bands at $823 \mathrm{~cm}^{-1}$ and $719 \mathrm{~cm}^{-1}$ completely vanished and turn up at $619 \mathrm{~cm}^{-1}$ and $534 \mathrm{~cm}^{-1}$ after deuteration (ISR $=1.33$ ), the bands having been assigned to the $\gamma(\mathrm{OH})$ and $\gamma(\mathrm{OD})$ modes of conformer $\mathbf{B}$ and A, respectively. The results presented above are in agreement with the data based on PED analysis (Table S3, SM) as well as the data obtained earlier for 5-methyl-3-nitro-2hydroxyacetophenone [29].

\subsubsection{The $v(\mathrm{C}=\mathrm{O})$ Stretching Mode}

It is noteworthy that the stretching vibration of the carbonyl group $(v(C=O))$ was the most sensitive to the conformational equilibrium [30,31]. According to IR and Raman spectra measured in the solid state (Figure S7, SM), only one band was observed in the $1800-1600 \mathrm{~cm}^{-1}$ range at $1650 \mathrm{~cm}^{-1}$ and was assigned to $v(C=O)$ mode (PED analysis, Table S2, SM). Interestingly, the $v(C=O)$ bands of both polymorphs were nearly the same, and therefore, demonstrated very little sensitivity to polymorphic changes. However, IR spectra under the matrix condition were characterized by two bands at $1700 \mathrm{~cm}^{-1}$ and $1667 \mathrm{~cm}^{-1}$, which were assigned to the $v(C=O)$ vibrations of conformers $\mathbf{A}$ and $\mathbf{B}$ (Figure 4), correspondingly. This statement is in accordance with our previous studies of the methyl derivative of $o$-hydroxy acetophenone [29].

\subsubsection{Nitro Group Mode}

Solid state. The bands most sensitive to polymorphic states were assigned to the nitro group vibrations. The bands at $1533 \mathrm{~cm}^{-1}\left(v^{\text {as }}\left(\mathrm{NO}_{2}\right)\right), 1346 \mathrm{~cm}^{-1}\left(v^{\text {sym }}\left(\mathrm{NO}_{2}\right)\right), 900 \mathrm{~cm}^{-1}$ $\left(\delta\left(\mathrm{NO}_{2}\right)\right)$ in the Raman spectrum and at $899 \mathrm{~cm}^{-1}\left(\delta\left(\mathrm{NO}_{2}\right)\right.$ in the IR spectrum shifted noticeably upon transitioning from polymorph I to polymorph II $\left(1540 \mathrm{~cm}^{-1}, 1357 \mathrm{~cm}^{-1}\right.$, $881 \mathrm{~cm}^{-1}$ in Raman and $894 \mathrm{~cm}^{-1}$ in IR spectra, Figure S7, SM). A large increase in intensity of the band at $1346 \mathrm{~cm}^{-1}$ was also detected in the Raman spectrum upon transition from polymorph I to polymorph II.

Matrix condition. Two intense bands at $1550 \mathrm{~cm}^{-1}$ and $1539 \mathrm{~cm}^{-1}$ as well as two bands at $1356 \mathrm{~cm}^{-1}$ and $1303 \mathrm{~cm}^{-1}$ observed in IR spectrum registered under the matrix condition (Figure 4) were assigned to asymmetric and symmetric vibrations of the nitro group of conformers $\mathbf{B}$ and $\mathbf{A}$, respectively. As for the solid state, the bands assigned to conformer B (cf. IR spectra obtained under the matrix condition and in the solid state, Figure 4 and Figure S7, SM) were absent in IR and Raman spectra.

\subsection{Spectral Changes under Phase Transition in the Solid State}

Regarding phase transition, no significant band splitting during the transition from one phase to the other was observed in IR spectra measured in the middle spectral range. However, the IR spectrum in the far-infrared range demonstrated visible changes (Figure S8, $\mathrm{SM})$. At higher temperatures (300-120 K) there were single bands at 454, 409, 350 and $182 \mathrm{~cm}^{-1}$, which split into doublets at the temperature below the phase transition. The IR spectra of polymorph II were measured to verify the results, which did not reveal the splitting of the abovementioned bands in the far-infrared range for the polymorph without the phase transition. The PED analysis showed that bands at 454, 350 and $182 \mathrm{~cm}^{-1}$ belonged to multicomponent modes (Table S2, SM). The intense band at $409 \mathrm{~cm}^{-1}$ in the IR spectrum was assigned to $v_{\sigma}(\mathrm{OHO})$ vibration due to a strong reduction of the intensity upon deutero replacement. The reliability of the assignment was also proved by IINS studies (Figure 5). 
For a deeper insight into the vibrational spectra, isotopic effect and conformational polymorphism we studied the IINS spectra of CNK and CNK-OD within the $1200-0 \mathrm{~cm}^{-1}$ range in the solid state (Figure 5). These spectra showed the presence of two polymorphic forms at low temperature and verified the correctness of the assignment of the vibrations of the hydroxyl group and the hydrogen bridge $\left(v_{\sigma}(\mathrm{OHO})\right)$.

Most bands of the measured IINS spectra of both isotopologues were doublets (Figure 5; in the figure, the doublets are marked by filled squares, circles and triangles). In the papers by Tomkinson [32] and Margues [33], it is stated that the split bands in the IINS spectra occurred as a result of two crystallographically and energetically non-equivalent modes. The doubling of bands in the IINS spectra was also supposed to result from the Davydov effect [34], which is the separation of energy levels ascribed to the same vibration due to the presence of several interacting molecular entities in the unit cell. Therefore, the splitting of the bands in the IINS spectra in both isotopologues was due to the presence of two polymorphic forms at $10 \mathrm{~K}$. Three bands at 949,916 and $895 \mathrm{~cm}^{-1}$ were observed within the range of $1000-850 \mathrm{~cm}^{-1}$, three of which were the result of th overlapping of two doublets: $949 / 916 \mathrm{~cm}^{-1}$ (circles) and 916/895 $\mathrm{cm}^{-1}$ (triangles). The doublet at 895/916 disappeared upon deuteration (cf. spectra CNK and CNK-OD, Figure 5) and appeared as a very small doublet at 656 and $676 \mathrm{~cm}^{-1}$. According to the calculated ISR coefficient (ISR $=1.35$ ) and the PED analysis (Table S5, SM), these bands were assigned to the $\gamma(\mathrm{OH})$ and $\gamma(\mathrm{OD})$ out-of-plane bending modes. The values of the $\gamma(\mathrm{OH})$ bands of IR and IINS spectra were compared in a qualitative way with the values obtained from the correlation $\mathrm{R}(\mathrm{OO})=3.01+0.0044 \times 10^{-4} \gamma(\mathrm{OH})$ (for $\mathrm{OHO}$ hydrogen bridges longer than $2.4 \AA$ ) presented in reference [35]. The position of the $\gamma(\mathrm{OH})$ band shifted towards the high frequencies alongside the strengthening of the hydrogen bond $\left(823 \mathrm{~cm}^{-1}\right.$ in matrix condition $<860 \mathrm{~cm}^{-1}$ in the solid state). This fact supports the tendency shown in the review by Novak [36] for medium-strong intramolecular hydrogen bonding.

\section{Materials and Methods}

\subsection{Chemicals}

Compounds and solvents were purchased from Sigma-Aldrich and used without purification. High-purity argon gas (N60 $=99.99990 \%)$ was obtained from Air Liquide. The deuterated sample was prepared by dissolving the product in deuterated methanol $\left(\mathrm{CH}_{3} \mathrm{OD}\right)$. The solution was heated to $60^{\circ} \mathrm{C}$ and refluxed for $20 \mathrm{~min}$. Then the methanol was removed by evaporation under reduced pressure. This procedure was repeated three times. The deuteration degree was estimated to be ca. $80-90 \%$.

\subsection{Computational Details}

Quantum-mechanical calculations using the B3LYP functional $[37,38]$ with the 6$311++\mathrm{G}(2 \mathrm{~d}, 2 \mathrm{p})[39,40]$ basis set were performed with the GAUSSIAN 16 program [41]. The non-adiabatic approach was used to calculate $\Delta E=f(\mathrm{~d}(\Theta))$ dependence. Structural parameters were optimized for each fixed angle, changing gradually by $10^{\circ}$. The potential energy distribution (PED) of the normal modes for each obtained equilibrium geometry was calculated using the internal coordinates by the GAR2PED program [42].

\subsection{Thermal Measurements}

Differential scanning calorimetry (DSC) experiments were recorded with PerkinElmer Model 8500 differential scanning calorimeter on the polycrystalline material in the temperature range of 100-300 K under a nitrogen atmosphere in hermetically sealed $\mathrm{Al}$ pans. Calibration was performed with $n$-heptane and indium as standards.

\subsection{NQR Measurements}

The powdered sample without further preparation was placed in a standard $5 \mathrm{~mm}$ glass sample tube, which was subsequently placed inside the probe of the NQR spectrometer. ${ }^{35} \mathrm{Cl}$ NQR spectra were recorded using NMR/NQR Tecmaq Redstone spectrometer 
by the single pulse method in the frequency range 35-37 MHz. The pulse duration was 3 $\mu \mathrm{s}$, followed by $1 \mathrm{~ms}$ acquisition and subsequent $400 \mathrm{~ms}$ delay time. The number of scans was ca. 3000. The temperature was controlled using an Oxford Instrument cryostat and stabilized with the precision better than $\pm 1 \mathrm{~K}$.

\subsection{Crystallographic Details}

The intensity data were collected at $100 \mathrm{~K}$ using a Kuma KM4CCD diffractometer and graphite-monochromated $\operatorname{MoK} \alpha(0.71073 \AA)$ radiation generated from an X-ray tube operating at $50 \mathrm{kV}$ and $35 \mathrm{~mA}$. The images were indexed, integrated, and scaled using the Oxford Diffraction data reduction package [43]. The experimental details together with crystallographic data are given in Table S5. An absorption correction was omitted. The structure was solved by direct methods using SHELXS97 [44] and refined by the full-matrix least-squares method on all $\mathrm{F}^{2}$ data (SHELXL97) [45]. Non-hydrogen atoms were refined with anisotropic thermal parameters; hydrogen atoms were included from $\Delta \rho$ maps and refined isotropically. The supplementary crystallographic data for this paper is deposited to Cambridge Crystallographic Data Centre (CCDC) under no. 1937047-1937049 for 5-chloro-3-nitro-2-hydroxyacetophenone. These data can be obtained free of charge via www.ccdc.cam.ac.uk/conts/retrieving.html (accessed on 11 May 2021) (or from the Cambridge Crystallographic Data Centre, 12 Union Road, Cambridge CB2 IEZ, UK: fax: (+44) 1123-336-033. e-mail: deposit@ccdc.cam.ac.uk). The molecular structures with atom labeling are shown in Figure S5 (SM).

\subsection{IR and Raman Measurements}

The standard infrared and Raman spectra were measured using Bruker IFS 66 FT-IR and Nicolet Magna 860 FT-Raman spectrometers in the solid state with a $2 \mathrm{~cm}^{-1}$ resolution, respectively. The In-Ga-Ar laser line at $1064 \mathrm{~nm}$ was employed for the Raman excitation measurements. To obtain matrices containing CNK, the crystalline sample was allowed to sublimate from a small electric oven located inside the vacuum vessel of the cryostat. The CNK vapours, mixed with a large excess of matrix gas (argon), were deposited onto a CsI window kept at $15 \mathrm{~K}$ in a closed cycle helium cryostat (APD-Cryogenics). The sample temperature was maintained with a temperature controller (Scientific Instruments 9700) equipped with a silicone diode and a resistive heater. Infrared spectra were recorded at 11 $\mathrm{K}$ between 4000 and $50 \mathrm{~cm}^{-1}$ with a resolution of $0.5 \mathrm{~cm}^{-1}$ by means of a Fourier transform IR spectrometer (Bruker IFS 66) equipped with a liquid $\mathrm{N}_{2}$ cooled MCT detector.

\subsection{Incoherent Inelastic Neutron Scattering (IINS) Measurement}

Neutron scattering data were collected at the pulsed IBR-2M reactor at the Joint Institute of Nuclear Research (Dubna, Russia) using the time-of-flight inverted geometry spectrometer NERA-PR at $10 \mathrm{~K}$. To avoid misunderstanding in the comparison of the IINS spectra, the samples of the studied compounds were measured as a powered substance.

\section{Conclusions}

To summarize, the paper showed an application of quantum-mechanical calculations for the detection of particular physical-chemical processes in a molecule. DFT calculations enabled the prediction of the possible observation of two phenomena for the studied compound: polymorphism in the solid state and the conformational equilibrium under the condition approaching to the gas phase. The first of the predicted phenomena-the existence of two polymorphs of the studied compound and the phase transition between them-was revealed by DSC and NQR techniques. The non-equivalency of the structures in crystal cells was reflected in the splitting of the bands in the IINS spectrum, and the bands in IR spectrum registered in far-infrared region.

The second of the predicted phenomena was the conformational equilibrium between two hydrogen bonds $\left(\mathrm{N}=\mathrm{O} \cdots \mathrm{H}-\mathrm{O}\right.$ and $\left.\mathrm{O}-\mathrm{H} \cdots \mathrm{O}=\mathrm{C}\left(\mathrm{CH}_{3}\right)\right)$. Two conformational forms detected in the matrix isolation conditions by infrared spectroscopy unambiguously proved 
this prediction. Complete assignments of spectral bands based on the PED analysis and isotopic substitution showed the presence of two conformers under the matrix condition and two polymorph forms in the solid state. The studies confirmed the agreement of the theoretical and experimental results.

Supplementary Materials: The following are available online, Figures S1-S8, Table S1-S5.

Author Contributions: Conceptualization, A.F.; methodology, Ł.H., P.S., A.K. and M.P.-K.; software, Ł.H., P.S., M.P.-K. and A.K.; validation, A.F.; formal analysis, all Authors; investigation, Ł.H., P.S., A.K., M.W., M.Y.M., P.M.T., M.P.-K. and A.F.; resources, P.M.T. and A.F.; data curation, Ł.H., P.S., A.K., M.W., M.Y.M., P.M.T., M.P.-K. and A.F.; writing—original draft preparation, Ł.H., P.S., A.K., M.W., M.Y.M., P.M.T., M.P.-K. and A.F.; writing-review and editing, A.F.; visualization, Ł.H., P.S., A.K., M.W., M.Y.M., P.M.T., M.P.-K. and A.F; supervision, A.F.; project administration, A.F; funding acquisition, M.Y.M., P.M.T. and A.F. All authors have read and agreed to the published version of the manuscript.

Funding: This research was funded by RSF, grant number no: 18-13-00050.

Institutional Review Board Statement: Not applicable.

Informed Consent Statement: Not applicable.

Data Availability Statement: All data associated with this article are included in Supplementary Materials.

Acknowledgments: This work was supported by RSF (no: 18-13-00050) grant. The Authors acknowledge the Wrocław Centre for Networking and Supercomputing Centres (WCSS) for providing computational time and facilities.

Conflicts of Interest: The authors declare no conflict of interest.

Sample Availability: Samples of the compound 5-chloro-3-nitro-2-hydroxyacetophenone are available from the authors.

\section{References}

1. Bernstein, J. Polymorphism in Molecular Crystals, 2nd ed.; Oxford University Press: Oxford, UK, 2008.

2. Cruz-Cabeza, A.J.; Bernstein, J. Conformational Polymorphism. Chem. Rev. 2014, 114, 2170-2191. [CrossRef] [PubMed]

3. Panda, M.K.; Centore, R.; Causà, M.; Tuzi, A.; Borbone, F.; Naumov, P. Strong and Anomalous Thermal Expansion Precedes the Thermosalient Effect in Dynamic Molecular Crystals. Sci. Rep. 2016, 6, 29610. [CrossRef] [PubMed]

4. Nangia, A. Conformational polymorphism in organic crystals. Acc. Chem. Res. 2008, 41, 595-604. [CrossRef] [PubMed]

5. Steed, K.M.; Steed, J.W. Packing Problems: High Z' Crystal Structures and Their Relationship to Cocrystals, Inclusion Compounds, and Polymorphism. Chem. Rev. 2015, 115, 2895-2933. [CrossRef]

6. Hilfiker, R. Polymorphism: In the Pharmaceutical Industry; Wiley-VCH: Weinheim, Germany, 2006.

7. Brittain, H.G. Polymorphism in Pharmaceutical Solids, 1st ed.; Marcel Dekker Inc.: New York, NY, USA, 1999.

8. Yu, L. Polymorphism in Molecular Solids: An Extraordinary System of Red, Orange, and Yellow Crystals. Acc. Chem. Res. 2010, 43, 1257-1266. [CrossRef]

9. Schmidtmann, M.; Gutmann, M.J.; Middlemiss, D.S.; Wilson, C.C. Towards proton transfer in hydrogen bonded molecular complexes: Joint experimental and theoretical modelling and an energy scale for polymorphism. CrystEngComm 2007, 9, 743-745. [CrossRef]

10. Bilton, C.; Howard, J.A.K.; Laxmi Madhavi, N.N.; Nangia, A.; Desiraju, G.R.; Allen, F.H.; Wilson, C.C. When is a polymorph not a polymorph? Helical trimeric O-H . . O synthons in trans-1,4-diethynylcyclohexane-1,4-diol. Chem. Commun. 1999, 1675-1676. [CrossRef]

11. Barnes, A.J. Matrix isolation studies of hydrogen bonding_An historical perspective. J. Mol. Struct. 2018, 1163, 77-85. [CrossRef]

12. Barnes, A.J.; Orville-Thomas, W.J.; Müller, A.; Gaufrès, R. (Eds.) Matrix Isolation Spectroscopy; Springer Publishing Company: Dordrecht, The Netherlands, 1981.

13. Nogueira, B.A.; Ildiz, G.O.; Canotilho, J.; Eusebio, M.E.S.; Henriques, M.S.C.; Paixao, J.A.; Fausto, R. 5-Methylhydantoin: From Isolated Molecules in a Low-Temperature Argon Matrix to Solid State Polymorphs Characterization. J. Phys. Chem. A 2017, 121, 5267-5279. [CrossRef]

14. Avadanei, M.; Kus', N.; Cozan, V.; Fausto, R. Structure and Photochemistry of N-Salicylidene-p-carboxyaniline Isolated in Solid Argon. J. Phys. Chem. A 2015, 119, 9121-9132. [CrossRef]

15. Mitchell, P.C.H.; Parker, S.F.; Ramirez-Cuesta, A.J.; Tomkinson, J. Vibrational Spectroscopy with Neutrons, with Applications in Chemistry, Biology, Materials Science and Catalysis; World Scientific: Singapore, 2005. 
16. Marques, M.P.M.; Valero, R.; Parker, S.F.; Tomkinson, J.; Batista de Carvalho, L.A.E. Polymorphism in Cisplatin Anticancer Drug. J. Phys. Chem. B 2013, 117, 6421-6429. [CrossRef] [PubMed]

17. Rivera, S.A.; Allis, D.G.; Hudson, B.S. Importance of Vibrational Zero-Point Energy Contribution to the Relative Polymorph Energies of Hydrogen-Bonded Species. Cryst. Growth Des. 2008, 8, 3905-3907. [CrossRef]

18. Johnson, M.R.; Trommsdorff, H.P. Vibrational spectra of crystalline formic and acetic acid isotopologues by inelastic neutron scattering and numerical simulations. Chem. Phys. 2009, 355, 118-122. [CrossRef]

19. Seliger, J.; Zagar, V. Hydrogen bonding and proton transfer in cocrystals of 4,4'-bipyridyl and organic acids studied using nuclear quadrupole resonance. Phys. Chem. Chem. Phys. 2014, 16, 18141-18147. [CrossRef] [PubMed]

20. Seliger, J.; Zagar, V.; Asaji, T.; Gotoh, K.; Ishida, H. A N-14 nuclear quadrupole resonance study of phase transitions and molecular dynamics in hydrogen bonded organic antiferroelectrics 55DMBP-H(2)ca and 1,5-NPD-H(2)ca. Phys. Chem. Chem. Phys. 2011, 13, 9165-9172. [CrossRef] [PubMed]

21. Orville-Thomas, W.J. Internal Rotation in Molecules; John Wiley \& Sons, Inc.: New York, NY, USA, 1974.

22. Filarowski, A.; Kochel, A.; Koll, A.; Bator, G.; Mukjerhee, S. Phase transition and intramolecular hydrogen bonding in nitro derivatives of ortho-hydroxy acetophenones. J. Mol. Struct. 2006, 785, 7-13. [CrossRef]

23. Kalenik, J.; Majerz, I.; Sobczyk, L.; Grech, E.; Habeeb, M.M.M. ${ }^{35} \mathrm{Cl}$ nuclear quadrupole resonance and infrared studies of hydrogen-bonded adducts of 2-chloro-4-nitrobenzoic acid. J. Chem. Soc. Faraday Trans. I 1989, 85, 3187-3193. [CrossRef]

24. Apih, T.; Gregorovic, A.; Zagar, V.; Seliger, J. Nuclear Quadrupole Resonance Study of Proton and Deuteron Migration in Short Strong Hydrogen Bonds Formed in Molecular Complex 3,5-Dinitrobenzoic Acid-Nicotinic Acid and in Deuterated 3,5Pyridinedicarboxylic Acid. J. Phys. Chem. C 2016, 120, 9992-10000. [CrossRef]

25. Asaji, T.; Hoshino, M.; Ishida, H.; Konnai, A.; Shinoda, Y.; Seliger, J.; Žagar, V. Phase transition and proton exchange in 1,3-diazinium hydrogen chloranilate monohydrate. Hyperfine Interact. 2010, 198, 85-91. [CrossRef]

26. Tobu, Y.; Ikeda, R.; Nihei, T.A.; Gotoh, K.; Ishida, H.; Asaji, T. Temperature dependence of one-dimensional hydrogen bonding in morpholinium hydrogen chloranilate studied by $\mathrm{Cl}-35$ nuclear quadrupole resonance and multi-temperature $\mathrm{X}$-ray diffraction. Phys. Chem. Chem. Phys. 2012, 14, 12347-12354. [CrossRef]

27. Dolinenkov, P.; Korneva, I.; Sinyavsky, N. The Distribution Change of Relaxation Times in Cl-35 NQR for Phase Transitions in p-Dichlorobenzene. Appl. Magn. Reson. 2015, 46, 17-24. [CrossRef]

28. Kovacs, A.; Izvekov, V.; Keresztury, G.; Pongor, G. Vibrational analysis of 2-nitrophenol. A joint FT-IR, FT-Raman and scaled quantum mechanical study. Chem. Phys. 1998, 238, 231-243. [CrossRef]

29. Pajakk, J.; Maes, G.; De Borggraeve, W.M.; Boens, N.; Filarowski, A. Matrix-isolation FT-IR and theoretical investigation of the competitive intramolecular hydrogen bonding in 5-methyl-3-nitro-2-hydroxyacetophenone. J. Mol. Struct. 2008, 880, 86-96. [CrossRef]

30. Konopacka, A.; Filarowski, A.; Pawełka, Z. Solvent influence on the transformation of intramolecular hydrogen bonds in 2-hydroxy-5-methyl-3-nitroacetophenone. J. Solution Chem. 2005, 34, 929-945. [CrossRef]

31. Sobczyk, L.; Chudoba, D.M.; Tolstoy, T.M.; Filarowski, A. Some Brief Notes on Theoretical and Experimental Investigations of Intramolecular Hydrogen Bonding. Molecules 2016, 21, 1657. [CrossRef] [PubMed]

32. Tomkinson, J.; Parker, S.F.; Braden, D.A.; Hudson, B.S. Inelastic neutron scattering spectra of the transverse acoustic modes of the normal alkanes. Phys. Chem. Chem. Phys. 2002, 4, 716-721. [CrossRef]

33. Marques, M.P.M.; Batista de Carvalho, L.A.E.; Valero, R.; Machado, N.F.L.; Parker, S.F. An inelastic neutron scattering study of dietary phenolic acids. Phys. Chem. Chem. Phys. 2014, 16, 7491-7500. [CrossRef]

34. Davydov, A.S. Teorya Molekularnyzh Eksitonov; Nauka: Moscow, Russia, 1968.

35. Howard, J.; Tomkinson, J.; Eckert, J.; Goldstone, J.A.; Taylor, A.D. Inelastic neutron scattering studies of some intramolecular hydrogen bonded complexes: A new correlation of $\gamma(\mathrm{OHO})$ vs $R(\mathrm{OO})$. J. Chem. Phys. 1983, 78, 3150-3155. [CrossRef]

36. Novak, A. Hydrogen bonding in solids correlation of spectroscopic and crystallographic data. Struct. Bonding 1974, 18, 177-216.

37. Becke, A.D. Density-functional thermochemistry. III. The role of exact exchange. J. Chem. Phys. 1993, 98, 5648-5652. [CrossRef]

38. Lee, C.; Yang, W.; Parr, R.G. Development of the Colle-Salvetti correlation-energy formula into a functional of the electron density. Phys. Rev. B 1988, 37, 785-789. [CrossRef] [PubMed]

39. McLean, A.D.; Chandler, G.S. Contracted Gaussian basis sets for molecular calculations. I. Second row atoms, Z = 11-18. J. Chem. Phys. 1980, 72, 5639-5648. [CrossRef]

40. Frisch, M.J.; Pople, J.A.; Binkley, J.S. Self-consistent molecular orbital methods 25. Supplementary functions for Gaussian basis sets. J. Chem. Phys. 1984, 80, 3265-3269. [CrossRef]

41. Frisch, M.J.; Trucks, G.W.; Schlegel, H.B.; Scuseria, G.E.; Robb, M.A.; Cheeseman, J.R.; Scalmani, G.; Barone, V.; Petersson, G.A.; Nakatsuji, H.; et al. Gaussian 16; Revision B.01; Gaussian, Inc.: Wallingford, CT, USA, 2016.

42. Martin, J.M.L.; Van Alsenoy, C. Gar2ped; University of Antwerp: Antwerpen, Belgium, 1995.

43. Oxford Diffraction Poland Sp. CryslAlis CCD; CryslAlis RED Version 1.171.13 beta (Release 14.11.2003) Copyright 1995-2003; Oxford Diffraction Ltd.: Abingdon, UK, 2003.

44. Sheldrick, G.M. SHELXS97 Program for Solution of Crystal Structure; University of Goettingen: Goettingen, Germany, 1997.

45. Sheldrick, G.M. SHELX197 Program for Refinement of Crystal Structure; University of Goettingen: Goettingen, Germany, 1997. 